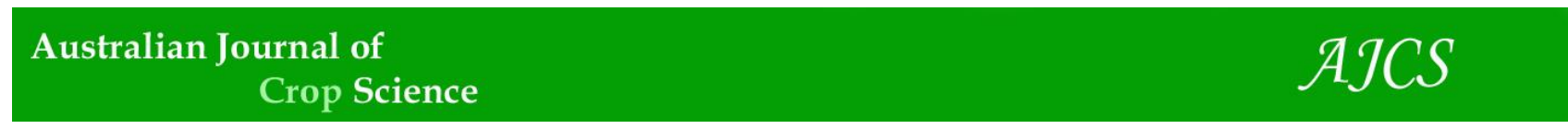

AJCS 12(03):430-434 (2018)

ISSN:1835-2707

doi: 10.21475/ajcs.18.12.03.pne863

\title{
Insecticide resistance of corn weevil populations from semi-arid regions
}

\author{
João Luciano de Andrade Melo Junior*, José Alexandre da Silva, Kléber Régis Santoro, César Auguste \\ Badji
}

Department of Agronomy, Federal Rural University of Pernambuco, Academic Unit of Garanhuns, Garanhuns, PE, Brazil

*Corresponding author: luciiano.andrade@yahoo.com.br

\begin{abstract}
Corn weevil (Sitophilus zeamais) is a key insect pest of stored corn in Brazil. Corn weevil infestations are traditionally controlled using insecticides. The intensive use of insecticidal compounds, however, may result in the development of insecticide-resistant populations and ultimately cause insecticide-based control measures to fail. The objective of the present work is to define the permethrin and pirimiphos-methyl resistance of $S$. zeamais populations collected from the semi-arid region of Pernambuco, Brazil. Insects were placed in glass bottles impregnated with dry insecticide residues at different concentrations. Deceased insects were counted $24 \mathrm{~h}$ after exposure. Concentration-response curves were generated by subjecting mortality results to Probit analysis. The Sete Lagoas population exhibited the lowest $50 \%$ mortality $\left(\mathrm{LC}_{50}\right)$ to permethrin, whereas the Lajedo population exhibited the lowest $\mathrm{LC}_{50}$ to pirimiphos-methyl. These populations were used the reference peremthrin- and pirimiphos-methyl-susceptible populations. The order of the $\mathrm{LC}_{50}$-based susceptibility of the populations to the two insecticides differed from that of the $\mathrm{LC}_{95}{ }^{-}$ based susceptibility. Six and eight populations showed a significant resistance ratio $\left(R_{50}\right)$ against permethrin and pirimiphosmethyl, respectively. The Brejão population presented the maximum resistance to pirimiphos-methyl $\left(R_{50}=26.7\right.$ and $\left.R R_{95}=57.4\right)$. All populations exhibited low but greatly varied pyrethroid resistance levels. This result, however, does not imply that the problem of pyrethroid resistance is minimized when resistance is substantial in the Brejão population.
\end{abstract}

Keywords: Development of insecticide-resistant populations; Key insect pest; Probit analysis; Sitophilus zeamais; Stored corn in Brazil.

Abbreviations: Cl 95\%_Confidence interval at 95\% probability; LC_Lethal concentration; RR_Resistance ratio; SE_Standard error of the estimate; [ [ $]^{\text {[ }}$ Chi-square.

\section{Introduction}

Corn weevil (Sitophilus zeamais Motschulsky, Coleoptera: Curculionidae) is a main insect pest of stored grains and is one of the most destructive and widely distributed pest insects in the world (Faroni and Souza, 2006). Guedes (1991) reported that corn weevils are a key pest of corn in Brazil. Corn weevil infestations can result in losses of up to $20 \%$ of the total production of stored grains. Corn weevil infestations are intensified in tropical regions given the favorable environmental conditions for the corn weevil development and reproduction throughout the year (Lorini et al., 2015).

Corn infestation by $S$. zeamais generally begins in the field long before storage. This fact, allied with the broad distribution and destructive capability of this insect, results in massive losses during the post-harvest period. Corn weevils are classified as an internal primary pest given their ability to attack the intact grain; their intensified actions in corn cause considerable quantitative and qualitative damages to corn production (Rees, 1996). Damages result from a reduction in the dry mass of the grain, the physical and physiological qualities of seed corn, and the nutritional and commercial value of the final products (Lorini, 2002).
Ribeiro et al. (2007) stated that corn weevil infestations under storage conditions are traditionally controlled with chemicals given their quick action, low cost, and easy application. Nonetheless, the indiscriminate use of chemical pesticides has favored the selection of populations with resistance against different chemical compounds, such as pyrethroids and organophosphates, in many countries, including Brazil (Santos et al., 2009). In addition, pest populations can remain resistant to a certain insecticide even after long periods without insecticidal exposure (Corrêa et al., 2008). The stability and severity of the insecticidal resistance of corn weevil populations from different regions of Brazil have been documented (Fragoso et al., 2007; Freitas et al., 2009; Pereira et al., 2009; Braga et al., 2011; Silva et al., 2013). Guedes et al. (1995) concluded that these populations have varying levels of resistance to pyrethroids and organophosphates. The occurrence of pyrethroid and organophosphate resistance has led to the use of constantly increasing concentrations and frequent applications of these pesticides or their substitution with highly toxic and expensive chemicals (Guedes et al., 2006). 
However, despite the well-known resistance of $S$. zeamais to pyrethroids and organophosphates, scientific work on the pyrethroid and organophosphate resistance of $S$. zeamais populations from the semi-arid region of Pernambuco, Brazil, remain lacking. Therefore, the present study aimed to determine the level of permethrin and pirimiphos-methyl resistance within regional populations of $S$. zeamais. The results of this study can be used to identify the most effective insecticide for controlling corn weevil infestations in this region.

\section{Results}

Concentration-response curves (Tables 1 and 2) were generated by fitting the Probit model to the mortality data obtained through definitive tests $\left(\chi^{2}\right.$ significant, $\left.p \leq 0,05\right)$. The Sete Lagoas population showed the lowest $50 \%$ mortality $\left(L_{50}\right)$ to permethrin (Table 1$)$, whereas the Lajedo population showed the lowest $\mathrm{LC}_{50}$ to pirimiphos-methyl (Table 2).

The $L C_{50}$ values of permethrin ranged from 7.6 (Sete Lagoas-MG) to 51.4 (Jacarezinho-PR) $\mu \mathrm{g} \cdot \mathrm{cm}^{-2}$. Thus, the $\mathrm{LC}_{50^{-}}$ based resistance ratios (RR) of the studied populations were higher by 1.10 - (Jupi-PE) to 6.76-fold (Jacarezinho-PR) than those of the reference susceptible population. Although the populations had different responses, their resistance levels were not substantially higher than those of populations collected from other localities. Excluding the value of 1.0 from the confidence intervals of the ratios (Robertson and Preisler, 1992) revealed that six populations had significant permethrin RRs. $\mathrm{LC}_{95}$ values varied from 37.4 (Caruaru-PE) to 565.1 (Jacarezinho-PR) $\mu \mathrm{g} \cdot \mathrm{cm}^{-2}$. The angular coefficients of the curves varied from 1.33 (Garanhuns Natto-PE) to 3.39 (São João-PE) for permethrin. Thus, the order of susceptibility of the populations based on $\mathrm{LC}_{50}$ differed from that based on $\mathrm{LC}_{95}$ (Table 1).

The $L_{50}$ values of pirimiphos-methyl ranged from 0.6 (Lajedo-PE) to 32.0 (Jacarezinho-PR) $\mu \mathrm{g} \cdot \mathrm{cm}^{-2}$. Excluding the value of 1.0 from the confidence interval of the ratios (Robertson and Preisler, 1992) revealed that eight S. zeamais populations had significant pirimiphos-methyl ratios. The $\mathrm{LC}_{50}$-based ratios of these populations were 1.17- (Jupi-PE) to 53.3-fold (Jacarezinho-PR) higher than those of the reference pirimiphos-methyl-susceptible population. The $\mathrm{RR}_{50}=26.7$ and $\mathrm{RR}_{95}=57.4$ of the Brejão population was significantly higher than those of the Pernambuco populations. The $\mathrm{LC}_{95}$ of pirimiphos-methyl varied from 1.0 (Lajedo-PE) to 261.0 (Jacarezinho-PR) $\mu \mathrm{g} \cdot \mathrm{cm}^{-2}$. The angular coefficients of the curves for pirimiphos-methyl varied from 1.80 (Jacarezinho-PR) to 8.52 (Bom Conselho-PE). Thus, similar to that for permethrin, the order of $\mathrm{LC}_{50}$-based susceptibility of the populations to pirimiphos-methyl differed from that of $L C_{95}$-based susceptibility of the populations to pirimiphos-methyl (Table 2). High angular coefficients are indicative of genetic variation among the individuals of a population. Thus, susceptibility tends to vary widely in response to the intensity of the stimulus (pesticide dose, concentration, and exposure duration). The range of responses justifies the use and discussion of $\mathrm{LC}_{95}$ in this work.

\section{Discussion}

The insecticide resistance of the Jacarezinho population has been intensively studied (Guedes et al., 2009). The insensitivity mechanism may be responsible for the insecticide resistance of the population, which has been maintained under laboratory conditions since 1987.

Guedes et al. (1995) posited that the recurrent use of the organochloride dichlorodiphenyltrichloroethane (DDT) during the 1980s may have provided an intense selection pressure that promoted the evolution of pyrethroid crossresistance in insect populations in Brazil (Côrrea et al., 2008; Braga et al., 2011; Silva et al., 2013). New insecticidal compounds, such as pyrethroids, organophosphates, or mixtures of the two, are now commonly used for controlling insect infestations after the agricultural use of DDT was prohibited. Nevertheless, the intensive use of these compounds have resulted in the development of insecticideresistant populations and ultimately caused insecticidebased control measures to fail, particularly when used to control infestations in warehouses (Guedes et al., 1995). Corrêa et al. (2011) reported that the majority of $27 \mathrm{~S}$. zeamais populations in Brazil are resistant to pyrethroids and pyrethroid + organophosphate mixtures.

The lack of susceptibility baseline values indicated that $S$. zeamais populations have evolved organophosphate resistance. In addition, mortality data indicated the emergence of a possible cross-resistance or multidrug resistance of these populations (Freitas et al., 2009).

The Brejão population was more resistant to pirimiphosmethyl than the Lajedo population. This difference was significant considering that both populations are derived from Pernambuco and suggested that control failures are already a potential problem in this region. The pesticide resistance of these populations is a likely consequence of the pest management and discontinuous nature of the corn storage process. The Brejão county has an intense historical practice of coffee cropping, which requires the use of phosphates and carbamates. Thus, the populations likely developed cross-resistance in response to these conditions. Pernambuco populations are still predominantly sensitive to organophosphates. Thus, the development of organophosphate resistance should be evaluated and monitored. Insecticides are frequently applied at inadequate and/or incorrect dosages in Pernambuco counties. In addition, the systemic use of different chemical insecticides regardless of the pest insect's presence is a common practice among farmers. Ribeiro et al. (2007) reported that that the rapid evolution of insecticide resistance in natural populations has become a main obstacle in the management of pest insects. Insects have a short life cycle and high fertility. These characteristics favor the development of populations with different genetic characters. The spread of resistance is related with the frequency of insecticide use. Moreover, insecticide resistance is a result of the selective pressure exerted by these toxic compounds and the inheritance of characteristics from resistant individuals. Individuals with mutations that confer insecticide resistance are more likely to survive insecticide treatments and contribute more offspring to the general population than susceptible individuals, thus increasing the frequency of insecticide resistance genes in coming generations (Li et al., 2007). The 
Table 1. Susceptibility of S. zeamais populations against peremthrin.

\begin{tabular}{lccccc}
\hline $\begin{array}{l}\text { S. zeamais } \\
\text { populations }\end{array}$ & $\begin{array}{c}\text { Angular } \\
\text { coefficient } \pm \\
\mathrm{SE}\end{array}$ & $\begin{array}{c}\mathrm{LC}_{50}(\mathrm{Cl} 95 \%) \\
\mu \mathrm{g} . \mathrm{cm}^{-2}\end{array}$ & $\begin{array}{c}\mathrm{LC}_{95}(\mathrm{Cl} 95 \%) \\
\mu \mathrm{g} . \mathrm{cm}^{-2}\end{array}$ & $\mathrm{RR}(\mathrm{Cl} 95 \%)$ & $\sigma^{[]^{2}}$ \\
\hline Sete Lagoas-MG & $1.93 \pm 0.23$ & $7.6(5.5-10.4)$ & $53.9(33.8-108.6)$ & 71.57 \\
Jupi-PE & $2.42 \pm 0.42$ & $8.3(5.7-12.4)$ & $39.9(23.5-107.9)$ & $1.10(0.70-1.75)$ & 33.32 \\
Caruaru-PE & $2.82 \pm 0.49$ & $9.7(7.2-13.6)$ & $37.4(23.7-89.5)$ & $1.28(0.86-1.94)$ & 33.05 \\
Lagoa do Ouro-PE & $2.47 \pm 0.87$ & $11.7(4.5-43.2)$ & $54.5(21.3-5266.3)$ & $1.54(0.81-2.98)$ & 8.01 \\
Lajedo-PE & $1.95 \pm 0.29$ & $13.2(8.8-20.1)$ & $91.6(51.0-245.8)$ & $1.74(1.05-2.90)^{*}$ & 45.90 \\
São João-PE & $3.39 \pm 0.40$ & $14.3(11.9-17.7)$ & $43.9(32.5-69.0)$ & $1.88(1.37-2.64)^{*}$ & 71.32 \\
Brejão-PE & $1.74 \pm 0.16$ & $27.9(21.5-36.1)$ & $246.0(165.9-417.5)$ & $3.67(2.39-5.71)^{*}$ & 123.18 \\
Garanhuns Natto-PE & $1.33 \pm 0.11$ & $29.3(21.6-39.4)$ & $503.2(310.2-962.0)$ & $3.85(2.25-6.69)^{*}$ & 130.84 \\
Bom Conselho-PE & $1.98 \pm 0.23$ & $35.3(25.6-48.5)$ & $238.7(152.0-465.5)$ & $4.64(3.05-7.19)^{*}$ & 74.27 \\
Jacarezinho-PR & $1.58 \pm 0.17$ & $51.4(35.8-73.5)$ & $565.1(329.7-1245.0)$ & $6.76(4.19-11.1)^{*}$ & 81.86 \\
\hline
\end{tabular}

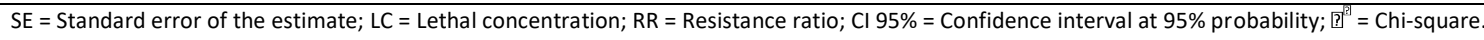

Table 2. Susceptibility of S. zeamais populations against pirimiphos-methyl.

\begin{tabular}{|c|c|c|c|c|c|}
\hline $\begin{array}{l}\text { S. zeamais } \\
\text { populations }\end{array}$ & $\begin{array}{c}\text { Angular } \\
\text { coefficient } \pm \\
\text { SE }\end{array}$ & $\begin{array}{c}\mathrm{LC}_{50}(\mathrm{Cl} 95 \%) \\
\mu \mathrm{g} . \mathrm{cm}^{-2}\end{array}$ & $\begin{array}{c}\mathrm{LC}_{95}(\mathrm{Cl} 95 \%) \\
\mu \mathrm{g} . \mathrm{cm}^{-2}\end{array}$ & RR (Cl $95 \%)$ & ]$^{[3}$ \\
\hline Lajedo-PE & $8.47 \pm 1.17$ & $0.6(0.5-0.7)$ & $1.0(0.9-1.2)$ & & 52.36 \\
\hline Jupi-PE & $3.52 \pm 0.48$ & $0.7(0.6-0.8)$ & $2.1(1.7-3.2)$ & $1.17(0.94-1.33)$ & 52.38 \\
\hline Garanhuns Natto-PE & $6.79 \pm 0.94$ & $0.8(0.7-0.9)$ & $1.4(1.2-1.7)$ & $1.33(1.11-1.27)^{*}$ & 51.94 \\
\hline Bom Conselho-PE & $8.52 \pm 1.21$ & $0.8(0.7-0.9)$ & $1.2(1.1-1.5)$ & $1.33(1.16-1.26)^{*}$ & 49.59 \\
\hline São João-PE & $6.22 \pm 0.98$ & $1.0(0.9-1.2)$ & $1.9(1.6-2.7)$ & $1.67(1.48-1.68)^{*}$ & 40.48 \\
\hline Sete Lagoas-MG & $6.11 \pm 0.98$ & $1.1(1.0-1.3)$ & $2.1(1.7-3.0)$ & $1.83(1.60-1.83)^{*}$ & 38.84 \\
\hline Caruaru-PE & $5.73 \pm 1.81$ & $1.4(1.0-2.1)$ & $2.7(1.9-10.5)$ & $2.33(1.87-2.45)^{*}$ & 10.01 \\
\hline Lagoa do Ouro-PE & $3.42 \pm 0.36$ & $1.6(1.4-1.8)$ & $4.8(3.8-6.6)$ & $2.67(2.14-2.72)^{*}$ & 92.33 \\
\hline Brejão-PE & $2.96 \pm 0.51$ & $16.0(11.2-24.3)$ & $57.4(34.9-144.7)$ & $26.7(20.4-29.9)^{*}$ & 33.82 \\
\hline Jacarezinho-PR & $1.80 \pm 0.22$ & $32.0(23.2-46.3)$ & $261.0(146.5-654.6)$ & $53.3(37.3-63.9)^{*}$ & 64.80 \\
\hline
\end{tabular}

$\mathrm{SE}=$ Standard error of the estimate; $\mathrm{LC}=$ Lethal concentration; RR = Resistance ratio; $\mathrm{Cl} 95 \%$ = Confidence interval at 95\% probability; ? $^{\mathrm{B}}=\mathrm{Chi}-\mathrm{square}$

Table 3. Origin from populations of $S$. zeamais used to evaluate resistance against the insecticides peremthrin- and pirimiphosmethyl.

\begin{tabular}{|c|c|c|c|c|}
\hline $\begin{array}{l}\text { S. zeamais } \\
\text { populations }\end{array}$ & City & Sampling location & Product & Sampling date \\
\hline Susceptible & Sete Lagoas $^{1}$ & Laboratory & & \\
\hline Resistant & Jacarezinho $^{2}$ & Laboratory & & \\
\hline 1 & Jupi & Grain Warehouse & Dry corn & April/2013 \\
\hline 2 & Brejão & Storeroom & Wet corn & April /2013 \\
\hline 3 & Caruaru & Metallic silo & Dry corn & June/2013 \\
\hline 4 & São João & Storeroom & Dry corn & August/2013 \\
\hline 5 & Lagoa do Ouro & Metallic silo & Dry corn & August/2013 \\
\hline 6 & Bom Conselho & Metallic silo & Dry corn & November/2013 \\
\hline 7 & Lajedo & Metallic silo & Dry corn & November/2013 \\
\hline 8 & Garanhuns Natto & Metallic silo & Dry corn & January/2014 \\
\hline
\end{tabular}

application period of permethrin should be extended to decrease selection pressure and the frequency of resistant genotypes.

Pyrethroid resistance is characterized by stability. Thus, to manage pyrethroid resistance efficiently in agricultural areas, pyrethroids should be alternately or simultaneously applied with newly registered insecticides that have different modes of action and with negative crossresistance. This application strategy will decrease the frequency of pyrethroid resistance genes in the population (Santos et al., 2009). Chemical rotation hinges on the possible disadvantage of adaptive resistant individuals.

As in previous studies, RR was evaluated on the basis of $L C_{50}$. $\mathrm{LC}_{95}$, however, is also an effective control parameter for field populations. Braga et al. (2011) stated that $\mathrm{LC}_{95}$ has excellent representativeness and allows for the adjustment of the Probit model (less amplitude of the mean standard errors), thus providing further credibility to the evaluation of lethal concentration and RR. The determination of $L_{50}$ and $R R$ allows the monitoring of temporal changes in the susceptibility of populations (Silva et al., 2013). The pirimiphos-methyl RR of the Jacarezinho and Brejão populations can be classified as severe. These populations may thus potentially harm stored grain.

The angular coefficient of the curve is inversely proportional to the mean standard error of the phenotypic distribution of insecticide tolerance in a population. According to Ribeiro et al. (2003), the variability between 
the individuals of the same population can be inferred from the slope of the curve. Fragoso et al. (2007) suggested that gradually sloping curves indicate greater genetic variability and suggest the presence of more than one genotype in the population. This pattern also indicates that insecticide response is highly heterogeneous and that the population has been exposed to different selective pressures. In addition, intra- and inter-population genetic diversity may explain the variability observed within these results. These scores will vary from year to year given the interference of various external factors. The data obtained by this study justify its implementation and corroborates its practical significance. The results of this study may support the development of management strategies against insecticide resistance. The successful implementation of these strategies may decrease losses incurred by the failure of agricultural pest control, especially in stored grains.

\section{Materials and methods}

\section{S. zeamais populations}

Ten different S. zeamais populations were used in this experiment. One population was obtained from the EMBRAPA-Corn and Sorghum National Research Center, Sete Lagoas-MG, Brazil. This population was maintained under laboratory conditions without insecticide exposure and was used as the reference pyrethroid-susceptible population. Another population originated from populations collected from warehouses in Jacarezinho-PR, Brazil. Previous studies have identified this population as resistant against pyrethroids. Thus, it was used as the reference pyrethroid-resistant population in the present study. Another S. zeamais population, designated as the Natto population, was collected from silos at the Rations Factory, Notaro Alimentos Ltda (Natto). The Natto population was treated with insecticides every four months on a rotating basis (Table 3 ). Other populations were collected from grainproducing counties in the semi-arid region of Pernambuco, Brazil, where control failures of insecticide application have been frequently reported (Table 3 ). Each population was cultivated on clean and dry corn grains. The grains were previously frozen for seven days at $-20{ }^{\circ} \mathrm{C}$ to eliminate any possible insect infestations. The populations were maintained at room temperature in glass containers $(1.2 \mathrm{~L})$ covered with thin, stiff, perforated cotton lids and were established from at least 500 individuals. The populations were individually preserved for several generations without exposure to insecticides at the Applied Entomology Laboratory of the Federal Rural University of Pernambuco of the Academic Unit of Garanhuns until the beginning of the experiments. Dry corn grains were periodically replaced to preserve populations.

\section{Insecticides and solvent}

The insecticides used in the bioassays (Technical Grade) were the pyrethroid permethrin (99.5\%) and the organophosphate pirimiphos-methyl (99.3\%). Both insecticides were procured from Sigma-Aldrich (Brazil) and were applied independently. Different concentrations of these chemicals were prepared with analytical grade acetone as a solvent (99.5\%, Modern Chemical Industry and Trade Ltda.).

\section{Concentration-response tests}

In vivo bioassays were performed following a completely randomized design in biochemical oxygen demand climatic chambers under $25 \pm 2{ }^{\circ} \mathrm{C}$, relative humidity of $70 \% \pm 5 \%$, and photoperiod of 12 hours. All tests were performed in experimental units comprising transparent cylindrical glass flasks with a volume of $5 \mathrm{~mL}$ and internal area of $18.8 \mathrm{~cm}^{2}$. The methodology was optimized to determine the optimal values for the following parameters: i- duration of insecticide exposure; ii- insecticide volume; and iii- number of insects per flask. The optimal parameters implemented in the model were as follows: $24 \mathrm{~h}$ of insecticide exposure, application volume of $0.1 \mathrm{~mL}$, and 10 individuals per flask.

After optimization, preliminary concentration-response tests were performed using six sequential dilutions (1000, $100,10,1,0.1$, and $0.01 \mu \mathrm{g} \cdot \mathrm{cm}^{-2}$ ) of the active compounds from permethrin and pirimiphos-methyl. Tests were performed separately with each insecticide. A total of $0.1 \mathrm{~mL}$ of pesticide solutions was added to each flask. The flasks were manually agitated to promote acetone evaporation and the uniform distribution of the insecticide in the solution. Subsequently, 10 unsexed adults of $S$. zeamais were placed into each flask. The number of dead individuals under each concentration was evaluated after $24 \mathrm{~h}$ of exposure. To standardize evaluation, insects with evidence of paralysis, which was defined as the inability to move after being touched with the bristles of a round-tip paintbrush for 60 seconds, were considered dead. After the evaluation, the lowest concentration of insecticide under which the maximum number of deaths occurred and the highest concentration of insecticide under which no death occurred were defined as the higher and lower extremes of insecticide concentration, respectively. Subsequently, new intermediary concentrations between these extremes were established. Additional tests were conducted with six different insecticide concentrations and one control (solvent only) with five replicates each and 350 individuals from each population. Definitive concentration tests were then performed with five replicates for each intermediary concentration in addition to the extremes. These tests constituted several treatments, which were varied on the basis of the extreme responses of each population, and a control (solvent only). A concentration-response curve for each population that had been exposed to a particular insecticide was constructed. A total of 350 or 400 individuals from each population were exposed. The mortality rates obtained through the definitive tests were adjusted in accordance with Abbott (1925). To obtain the final concentration-response curves, the adjusted results were then analyzed through Probit analysis with the PROC PROBIT procedure packaged in the statistical software SAS 9.0. RRs were calculated by dividing the LC of a population under study by its respective LC from the most susceptible population. These ratios were considered significant when the confidence intervals at $95 \%$ of probability did not include the value of 1.0 (Robertson and Preisler, 1992). 


\section{Conclusion}

There are strong evidences of cross resistance against pyrethroids and/or multiple resistance to pyrethroids and organophosphates. Considering semi-arid region of Pernambuco state, Brazil, there are problems of control failure of S. zeamais with the use of phosphorous. Mortality ratios in Jacarezinho evidenced other mechanisms of resistance, in addition to insensibility of the target site.

\section{Acknowledgment}

Corresponding author thanks Coordination for the Improvement of Higher Education Personnel by the granting the scholarship.

\section{References}

Abbott WS (1925) A method of computing the effectiveness of an insecticide. J Econ Entomol. 18(1): 265-266.

Braga LS, Corrêa AS, Pereira EJG, Guedes RNC (2011) Face or flee? Fenitrontion resistance and behavioral response in populations of the maize weevil, Sitophilus zeamais. J Stored Prod Res. 47(3): 161-167.

Corrêa AS, Braga EMG, Pereira EJG, Guedes RNC (2011) Insecticide resistance, mixture potentiation and fitness in population of the maize the weevil, Sitophilus zeamais. Crop Prot. 30(12): 1655-1666.

Corrêa AS, Santos CT, Oliveira EE, Tolledo JS, Cordeiro EMG, Guedes RNC (2008) Custo adaptativo da resistência através da competição entre populações susceptíveis de Sitophilus zeamais (Coleoptera: Curculionidae) e resistentes a piretróides. Revista Brasileira de Armazenamento. 33(2): 19-28.

Faroni LRA, Souza AH (2006) Aspectos biológicos e taxonômicos dos principais insetos-praga de produtos armazenados. In: Almeida FAC, Duarte MEM, Mata MERMC. Tecnologia de Armazenagem em Sementes, eds. UFCG, Campina Grande, pp.371-402.

Fragoso DB, Guedes RNC, Oliveira MGA (2007) Partial characterization of glutathione S-transferases in pyrethroid-resistance and susceptible populations of the maize weevil, Sitophilus zeamais. J Stored Prod Res. 43(10): 167-170.

Freitas CJP, Pereira EJG, Cordeiro EMG, Della Lucia TMC, Tótola MR, Guedes RNC (2009) Organophosphate resistance in the maize weevil Sitophilus zeamais: magnitude, costs and behavior. Crop Prot. 28(2): 168-173.

Guedes NMP, Guedes RNC, Ferreira GH, Silva LB (2009) Flight take-off and walking behavior of insecticidesusceptible and resistant-strains of Sitophilus zeamais exposed to deltamethrin. Bull Entomol Res. 99(4): 393400.

Guedes RNC, Oliveira EE, Guedes NMP, Ribeiro BM, Serrão JE (2006) Cost and mitigation of insecticide resistance in the maize weevil, Sitophilus zeamais. Physiol Entomol. 31(1): 30-38.
Guedes RNC, Lima JOL, Santos JP, Cruz CD (1995) Resistance to DDT and pyrethroids in Brazilian populations of Sitophilus zeamais Motsch. (Coleoptera: Curculionidae). J Stored Prod Res. 31(2): 145-150.

Guedes RNC (1991) Resistência a inseticidas: desafio para o controle de pragas de grãos armazenados. Revista Seiva. 50(99): 24-29.

Li X, Schuler MA, Berenbaum MR (2007) Molecular mechanisms of metabolic resistance to synthetic and natural xenobiotics. Annu Rev Entomol. 52(1): 231-253.

Lorini I, Krzyzanowski FC, França-Neto JB, Henning AA, Henning FA (2015) Manejo integrado de pragas de grãos e sementes armazenadas. Brasília, Embrapa, 72p.

Lorini I (2002) Descrição, biologia e danos das principais pragas de grãos armazenados. In: Irineu L, Miike LH, Scussel VM. Armazenagem de Grãos, eds. Instituto Biogeneziz, Campinas, pp.379-397.

Pereira CJ, Perira EJG, Cordeiro EMG, Lucia TMCD, Tótola MR, Guedes RNC (2009) Organophosphate resistance in maize weevil Sitophilus zeamais: Magnitude and behavior. Crop Prot. 28(2): 168-173.

Robertson JL, Preisler HK (1992) Pesticide Bioassays with Arthropods. Boca Raton, CRC Press, 199p.

Rees DP (1996) Coleoptera. In: Subramanyam BH, Hagstrum DW. Integrated Management of Insects in Stored Products, eds. Marcel Dekker, New York, pp.1-39.

Ribeiro B, Guedes RNC, Côrrea AS, Santos CT (2007) Fluctuating asymmetry in insecticide-resistant and insecticide-susceptible strains of the maize weevil, Sitophilus zeamais (Coleoptera: Curculionidae). Arch Environ Contam Toxicol. 53(1): 77-83.

Ribeiro BM, Guedes RNC, Oliveira EE, Santos JP (2003) Insecticide resistance and synergism in Brazilian populations of Sitophilus zeamais (Coleoptera: Curculionidae). J Stored Prod Res. 39(1): 21-31.

Santos JC, Faroni LRD, Simões RO, Pimentel MAG, Sousa AH (2009) Toxicidade de inseticidas piretróides e organofosforados para populações brasileiras de Sitophilus zeamais (Coleoptera: Curculionidae). Biosci J. 25(6): 75-81.

Silva LB, Silva LS, Mancin AC, Carvalho GS, Silva JC, Andrade LH (2013) Comportamento do gorgulho-do-milho frente à doses de permetrina. Com Sci. 4(1): 26-34. 